\title{
PREDICTING PERSONAL EXPOSURE LEVELS TO CARBON MONOXIDE (CO) IN TAIPEI, BASED ON ACTUAL CO MEASUREMENTS IN MICROENVIRONMENTS AND A MONTE CARLO SIMULATION METHOD
}

\author{
Jyh-Jian Liu, ${ }^{*}$ Chang-Chuan Chan $\dagger$ and Fu-Tien Jeng* \\ * National Taiwan University, Graduate Institute of Environmental Engineering, 21 Fl, No. 77, Sec. 2, \\ Tun-Hwa S. Road, Taipei 106, Taiwan; † National Taiwan University, College of Public Health, \\ Institute of Occupational Medicine and Industrial Hygiene, Taipei, Taiwan
}

(First received 1 April 1993 and in final form 20 September 1993)

\begin{abstract}
In order to evaluate the severity of carbon monoxide (CO) pollution in Taipei, this study conducted a survey of commuting patterns (in a district) for random samples of primary school students and adult workers, and carried out $C O$ measurements in vehicles and near roadsides. A Monte Carlo simulation was then implemented to estimate 1 - and $8-\mathrm{h} \mathrm{CO}$ exposure levels for the population. The microenvironment of the roadside included both the sidewalk and the corridor (a sheltered walkway farther removed from the road than the sidewalk). By computer simulations, this study showed that commuters on motorcycles and public buses were exposed to the highest $\mathrm{CO}$ exposure levels among all commuters on the roads in Taipei. This study also demonstrated that the Monte Carlo simulation method could better estimate CO exposure levels for the general public. It was found that roadside-fixed monitoring stations operated by the Taipei BEP (Bureau of Environmental Protection) underestimated the general population's 1-h CO exposure levels. For adult workers, the roadside-fixed monitoring stations reasonably estimated the roadside business workers' 8-h CO exposure levels, but overestimated the exposure levels of general adult workers commuting by public bus, except for bus drivers whose $\mathrm{CO}$ exposure levels were underestimated. It is suggested that the computer simulation method can be used to better guide air quality management plans instead of only using the fixed-site monitoring data. The simulated results indicate that the $\mathrm{CO}$ exposure levels of commuters on motorcycles and public buses are high enough that prompt control measures are warranted in Taipei.
\end{abstract}

Key word index: Monte Carlo simulation, carbon monoxide, urban area, exposure assessment, representativeness of fixed stations.

\section{INTRODUCTION}

Vehicular emissions have been identified as the most important sources of many air pollutants in Taipei, Taiwan. A recent study showed that mobile sources contributed about $98 \%$ of $\mathrm{CO}$ emissions in Taipei. Among mobile sources, motorcycles contribute as much as $44 \%$ of total CO emissions (ICF KE et al., 1991). In Taipei (272 square kilometers, 12 administrative districts), there are about 4100 vehicles $(66 \%$ of which are motorcycles and $30 \%$ of which are light duty gasoline cars) and 10,000 persons per square kilometer (Taiwan EPA, 1991). Furthermore, the population density $(25,000$ persons per square kilometer) is higher in Taipei's central area (including 65 square kilometers, 7 districts) and the motor vehicle emission intensity is about $\mathbf{4 0 0 0}$ metric tons per square kilometer per year. Many people work and live in proximity to main traffic roads in such a crowded city with such a high traffic emission load. Thus the air pollution problem, especially that pollution caused by vehicular emissions, is serious and there is much concern about population exposure levels. $\mathrm{CO}$ was considered an appropriate indicative air pollutant for our investigation of the urban vehicular emission problem in Taipei.

The Taipei environmental authority (Bureau of Environmental Protection. BEP) has set up 15 fixed monitoring stations to measure ambient air quality. Three of these located near roadways are classified as roadside stations and are thought to be representative of roadside $\mathrm{CO}$ concentrations. The municipal fixed site monitoring results are usually used to guide control strategies designed to attain national ambient air quality standards (NAAQS). Since NAAQS are based on public health considerations, measured concentrations need to be comparable to people's real exposure.

In urban areas, there are about three ways to estimate personal exposure levels to $\mathrm{CO}$. The first way is simply to rely on the fixed site measurements alone. Although experts have long doubted the suitability of applying fixed site measurements alone for exposure level estimation (Cortese and Spengler, 1976; Chan 
et al., 1991), this method is still widely used to guide air pollution control policy in many nations, including Taiwan. The second way is to improve the quality of $\mathrm{CO}$ dispersion models in urban areas. Some of the improved models are the CAL3QHC model (U.S. EPA, 1990), the ROADWAY model (Eskridge, 1987), and street canyon models (Hoydysh, 1988). The third way is to establish $\mathrm{CO}$ exposure models using computer simulations that combine $\mathrm{CO}$ concentrations in microenvironments with time activity data (indirect measurement), excluding direct personal exposure measurement. One drawback of the direct measurement method is that it is very expensive and labor-intensive (Sexton and Ryan; 1988). Some more reasonable and realistic modeling approaches (indirect measurement) to estimate $\mathrm{CO}$ exposure levels have been developed. For example, the Simulation of Human Activity and Pollutant Exposure model (SHAPE) (Ott et al., 1988) and various Monte Carlo simulation models (Ott, 1983-84; Ryan et al., 1988; Fingleton et al., 1991; Billick et al., 1991; Johnson et al., 1990). In Taipei, based on past experiences (ICF $\mathrm{KE}$ et al., 1991), the microscale dispersion models, such as the CALINE4 and ROADWAY, were not successful in estimating $\mathrm{CO}$ concentrations on the streets. The failure of these modeling methods were possibly due to the particular features of complex urban settings ir Taipei, such as the relatively high density of motor vehicles, roads, and buildings.

The purposes of this study are (1) to collect commuter pattern data; (2) to carry out a survey of $\mathrm{CO}$ concentrations in selected microenvironments affected by vehicular emissions, such as in commuting vehicles, roadsides including both the sidewalk and the corridor (a sheltered walkway farther removed from the road than the sidewalk), bus stops, residential areas, and school areas; (3) to conduct Monte Carlo simulations (indirect approach) to estimate $\mathrm{CO}$ exposure levels for the population and to find the most dominant factors or events; (4) to make a comparison of the Monte Carlo simulated CO exposure levels with the fixed site monitoring data. The study estimated the population's $\mathrm{CO}$ exposure levels in Taipei, reflecting the special characteristics of life style, urban setting, and the strength of traffic emissions. A comparison between the fixed site measurements and the Monte Carlo simulation method showed that the fixed site stations do not adequately represent $\mathrm{CO}$ exposure levels for the urban population.

\section{EXPERIMENTAL METHOD}

\section{Commuting patterns}

In 1990, a questionnaire survey was conducted to establish the commuting patterns of students and adult workers in the Ta-An district, Taipei. The Ta-An district, located in Taipei's central area, was selected as a representative target population area (11 square kilometers, 100,000 household units, general socioeconomic class, population density of 31,000 persons per square kilometer, and 65,5 , and $35 \%$ of the area in the district for residential, commercial, and open public use, respectively). A stratified cluster sampling was used to select student participants in this study. First, three grades in each primary school in the district were randomly selected. Secondly, all students from two random classes in each grade from all the eight schools were asked to fill out questionnaires, which amounted to a sample size of 1244 student participants. For adult participants, 350 families were first randomly selected from the district. Then, all working adults aged over $24 \mathrm{yr}$ in each family were selected to participate. A total of 622 workers filled out questionnaires. Information about commuting modes, duration and starting times of each trip, and routes of each trip were obtained in the questionnaires.

\section{Carbon monoxide measurements}

The $\mathrm{CO}$ concentrations were measured for three transportation modes: bus, private car, and motorcycle. Samples were collected over three time intervals in the day: morning rush hour, midday, and evening rush hour. The survey considered variables such as commuting mode and time interval during the day, but due to limited resources, did not control for factors of window position, ventilation status, vehicle age etc., and seasonal, daily, route. or geographical variance. For these moving samples, the air was collected into a 5 / Tedlar bag by a small pump (SKC Inc., Model 224) carried by team workers (as a commuter) in or on vehicles following trips along the six major transportation mains in Taipei. Approximately $5 /$ of air were sampled over $30-50$ min using flow rates of about $80-130 \mathrm{ml} \mathrm{min}^{-1}$ per trip. These samples were then analysed by a NDIR-based $\mathrm{CO}$ analyser (Horiba Inc., APMA Model 350E). In order to compare the concentrations and obtain diurnal variations. the same type of $\mathrm{CO}$ analyser was used to monitor $\mathrm{CO}$ concentrations continuously for $24 \mathrm{~h}$ at 20 fixed stations set at corridors (designated as "corridor station") of main roads covering Taipei's central area. Simultaneously, moving air samples were collected in vehicle emissions-associated microenvironments, including roadsides, bus stops, small lanes in residential areas, and in schools near these 20 corridor stations. The $\mathrm{CO}$ field surveys were carried out between December 1989 and February 1991.

In addition, we collected CO monitoring data from 1990 from three fixed-site, continuous monitoring stations operated by the Bureau of Environmental Protection (BEP) of the Taipei City government. Among them, two stations (BEP22, BEP23) were placed near main roads (designated as "roadside station") and the other one (BEPO2) was located in a residential area (designated as "regional station"). The heights of sampling inlets are about $2.5 \mathrm{~m}$ for the roadside stations, and about $12 \mathrm{~m}$ for the regional stations. The roadside stations were $1-3 \mathrm{~m}$ away from traffic lanes, and the regional station was located around the center of the residential area. The traffic flow data were collected from the local traffic authority's annual report.

\section{Monte Carlo simulation}

In order to estimate the most serious and common exposure events to the general population in Taipei, the study applied the Monte Carlo method to simulate exposure level distributions for the general commuters and occupational drivers. The exposure model can be expressed as:

$$
E_{i j}=\frac{1}{T} \int_{T} C_{i j} \cdot t_{i j}
$$

where $E_{i j}$ is exposure level indicated as the average $\mathrm{CO}$ concentration over a period of exposure time $(T, 1-$ or $8-\mathrm{h})$, $C_{i j}$ is the CO concentration of commuting mode (or scenarios) $i$ in time interval $j$ during the day, $t_{i j}$ is the duration of commuting mode $i$ in time interval $j$. For 1 -h simulations, $t_{i j}$ was randomly drawn from the surveyed commuting duration data set of commuting mode $i$ of time interval $j$ (morning rush 
Table 1. The commuting patterns for primary school students and adult workers in Taipei

\begin{tabular}{|c|c|c|c|c|}
\hline \multirow[b]{2}{*}{ Commuting mode } & \multirow[b]{2}{*}{$N$} & \multirow[b]{2}{*}{$(\%)$} & \multicolumn{2}{|c|}{$\begin{array}{l}\text { Commuting duration (h) } \\
\text { Arithmetic mean (S.D.) }\end{array}$} \\
\hline & & & Leaving home & Leaving school/workplace \\
\hline Students & 1244 & 100 & $0.34 *$ & $0.43^{*}$ \\
\hline Walking & 721 & 58 & $0.23 \quad(0.15)$ & $0.28 \quad(0.19)$ \\
\hline Bicycle & 12 & 1 & $0.33(0.24)$ & $0.52 \quad(0.48)$ \\
\hline Public bus & 361 & 29 & $0.50 \quad(0.29)$ & $0.67 \quad(0.36)$ \\
\hline Motorcycle & 13 & 1 & $0.38 \quad(0.23)$ & $0.45 \quad(0.21)$ \\
\hline Private car & 124 & 10 & $0.47 \quad(0.29)$ & $0.58 \quad(0.31)$ \\
\hline Misc. & 13 & 1 & $0.82 \quad(0.44)$ & $1.0 \quad(0.35)$ \\
\hline Adult workers & 622 & 100 & $0.62 \dagger$ & $0.74+$ \\
\hline Walking & 75 & 12 & $0.27 \quad(0.17)$ & $0.30 \quad(0.20)$ \\
\hline Bicycle & 25 & 4 & $0.31 \quad(0.22)$ & $0.33 \quad(0.30)$ \\
\hline Public bus & 162 & 26 & $0.82 \quad(0.44)$ & $1.0 \quad(0.50)$ \\
\hline Motorcycle & 174 & 28 & $0.53 \quad(0.26)$ & $0.60 \quad(0.30)$ \\
\hline Private car & 156 & 25 & $0.63 \quad(0.30)$ & $0.76 \quad(0.40)$ \\
\hline Misc. & 30 & 5 & $0.78 \quad(0.38)$ & $0.86 \quad(0.51)$ \\
\hline
\end{tabular}

* Leave home at 7:10 a.m. (median) and leave school at 4:15 p.m. (median).

† Leave home at 7:45 a.m. (median) and leave workplace at 5:30 p.m. (median).

S.D., standard deviation.

Table 2. The measured $\mathrm{CO}$ concentrations (ppm) in various indoor and outdoor microenvironments *

\begin{tabular}{lrrrrr}
\hline Location & $N$ & Arithmetic mean & Min. & Max. & S.D. \\
\hline In vehicle & & & & & \\
$\quad$ On motorcycle & 295 & 17.5 & 2.9 & 126 & 14 \\
$\quad$ In bus & 94 & 11.6 & 3.5 & 37 & 6 \\
$\quad$ In private car & 30 & 11.0 & 4.5 & 20 & 4 \\
Near roadway, outdoor & 113 & 13.0 & 1.3 & 42 & 8 \\
$\quad$ At bus stop & 854 & 8.1 & 0.5 & 101 & 7 \\
On roadside/corridor & 381 & 7.8 & 0.5 & 101 & 8 \\
$\quad$ Moving along roadside & 473 & 8.3 & 0.7 & 40 & 7 \\
$\quad$ Fixed at corridors & 127 & 2.5 & 0.5 & 7 & 1 \\
Residential area, outdoor & 17 & 1.6 & 0.7 & 6 & 2 \\
School area, outdoor & & & & & \\
\hline
\end{tabular}

*Sampling durations were 30-50 min, except at corridor stations where durations were $60 \mathrm{~min}$. Samples were taken during the time period of 7:00-19:00.

hour or evening rush hour) (Table 1 ), and $C_{i j}$ was randomly drawn from measured $\mathrm{CO}$ concentrations from corresponded location $i$ of time interval $j$. For commuting duration less than $1 \mathrm{~h}, C_{i j}$ of the rest of $1 \mathrm{~h}$ was assumed to be background levels of $1.6 \mathrm{ppm}$ (in school) for students and $2.5 \mathrm{ppm}$ (in office) for adult workers, based on the arithmetic means of $\mathrm{CO}$ concentrations in the school areas and residential areas (as shown in Table 2). Three likely 8-h exposure scenarios were assumed (Table 4). For 8 -h simulations, $t_{i j}$ was the duration of scenario $i$ and $C_{i j}$, as said above, was randomly drawn. The exposure model, equation (1), assumes that $C_{i j}$ is independent of $t_{i j}$, that the exposure events occurred unrelatedly, and that the SHAPE type model's assumptions (concentration superimpose hypothesis) are true. The Monte Carlo simulation was implemented by an algorithm programmed with SAS statistical software (Release 6.03 , SAS Ins., Inc.) to randomly and uniformly draw (1000) samples from measured data sets (per trial). The simulation process determined the expected $\mathrm{CO}$ exposure level distributions and was repeated five times in this smallscale study. The simulated maximum exposure value, and the median and range of exceedance (percent of which the simulated exposure levels exceeded the NAAQS of $35 \mathrm{ppm}$ (for $1 \mathrm{~h}$ ) or $9 \mathrm{ppm}$ (for $8 \mathrm{~h}$ )) in five trials for each commuting mode and scenario are presented in Tables 3 and 4 . The $C O$ exposure exceedances were further weighted by the population-fraction (as shown in the third column of Table 1) for each commuting mode to estimate the expected probability of the $1 \mathrm{~h} \mathrm{CO}$ exposure level exceeding the NAAQS for the general population in Taipei.

\section{Quality assurance and quality control}

The $\mathrm{CO}$ analysers were calibrated weekly by U.S. EPA traceable span gas. The accuracy of the $\mathrm{CO}$ analysers was controlled to be within $0.5 \mathrm{ppm}$ throughout the experimental period. Those trials whose samples were beyond the control range were eliminated. Duplicate samples were collected and analysed to assess the precision of the Tedlar bag sampling method and the difference between the moving sampling and fixed site methods. The relative percent difference between the duplicate samples was found within $10 \%$. 


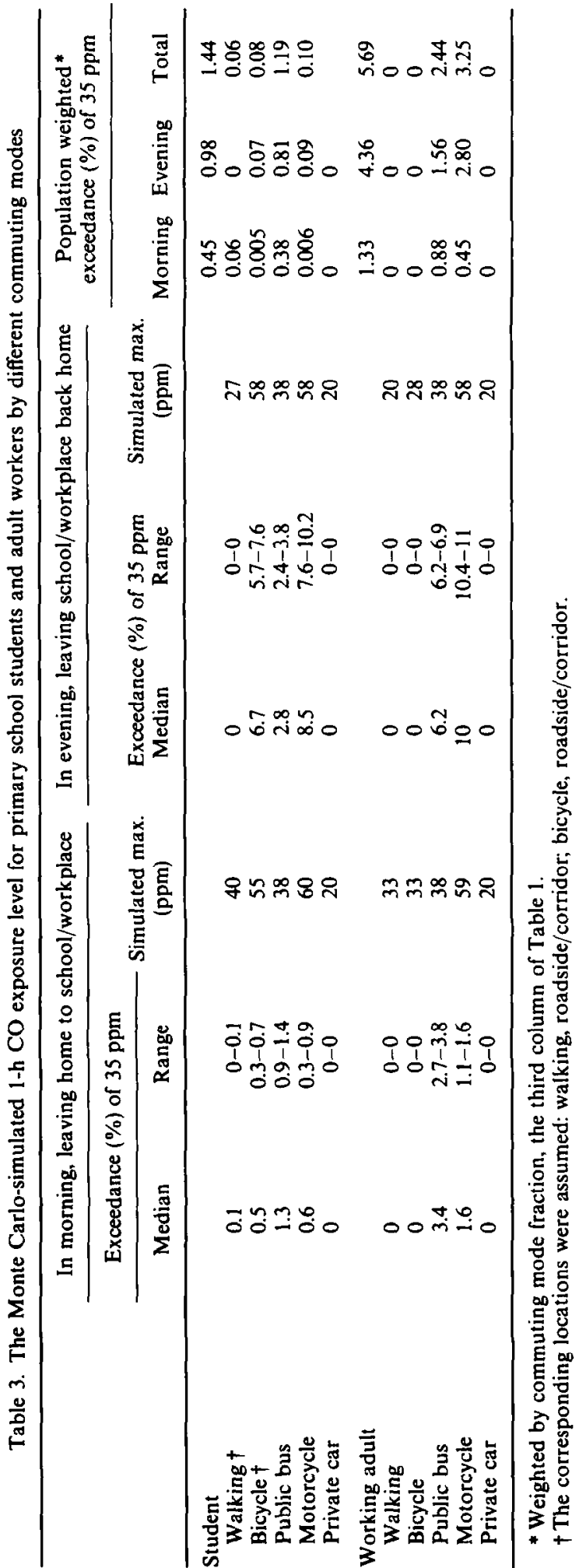

There was a significant difference in the commuting patterns and duration of commute between students and adult workers. Most students commuted between their homes and schools either by walking $(58 \%)$ or by riding on public buses $(29 \%)$. In contrast, most adult workers commuted between their homes and workplaces by motorcycle $(28 \%)$, public bus $(26 \%)$, or in private cars $(25 \%)$ (Table 1). Commuting by bicycle was rare. The adult workers' commuting duration each day was about twice as long as the students" $(1.36 \mathrm{~h}$ vs $0.77 \mathrm{~h})$. Duration of commute also varied with commuting modes. Commuters using public buses had the longest commuting duration $(1.82 \mathrm{~h}$ for adult workers and $1.17 \mathrm{~h}$ for students), and those that walked had the shortest commuting duration $0.57 \mathrm{~h}$ for adult workers and $0.51 \mathrm{~h}$ for students). Adult workers usually started their morning commutes $35 \mathrm{~min}$ later $(7: 45 \mathrm{a} . \mathrm{m}$. vs $7: 10 \mathrm{a} . \mathrm{m}$.) than students and started their afternoon commutes $75 \mathrm{~min}$ later (5:30 p.m. vs $4: 15$ p.m.). The adult workers who commuted by motorcycles and public buses have greater vehicle-emitting pollutant exposure levels than students because they had longer commuting durations (Table 3). The surveyed commuting pattern in Table 1 shows two characteristics of commuting in Taipei: popularity of transportation mode and commuting duration of two types of cohorts, both of which are essential when assessing and planning control strategies for controlling population exposure level to pollutants, and which are different in the developing countries from the developed countries. The wide variation in commuting patterns in the Taipei population demonstrates that personal exposure levels cannot be sufficiently well represented by the fixed site monitoring stations alone.

The CO concentrations (average) in Taipei were significantly higher than in surveys from the U.S. which reported lower $\mathrm{CO}$ concentrations by 3-4 ppm in vehicles and near roads outdoor (Ott et al., 1988). As expected, the $\mathrm{CO}$ concentration was very high on roadways, and rapidly decreased from the center of the roads to the roadsides. The highest $\mathrm{CO}$ concentrations were measured inside vehicles $(17.5 \mathrm{ppm}$ on motorcycles, $11.6 \mathrm{ppm}$ in public buses, and $11.0 \mathrm{ppm}$ in private cars), while the lowest were in residential areas (2.5 ppm) and schools (1.6 ppm) (Table 2). This trend generally agrees with the dispersion phenomena of $\mathrm{CO}$ from the line sources on the road to farther areas (Hewitt, 1992). The relatively high CO concentrations at bus stops (13.0 ppm) are one particular feature of CO pollution in Taipei. This is possibly due to many buses idling at the stops and the induced acceleration, deceleration and low traffic speed near bus stops. On the other hand, the $\mathrm{CO}$ concentrations were comparatively low in residential areas and schools, which were usually more than $30 \mathrm{~m}$ away from the roads. The findings imply that outdoor $\mathrm{CO}$ concentrations in residential areas and schools might not be an import- 
Table 4. The Monte Carlo-simulated 8-h CO exposure level for adult workers, roadside business workers, and bus drivers in Taipei

\begin{tabular}{|c|c|c|c|c|}
\hline & \multirow[b]{2}{*}{ Scenarios } & \multirow{2}{*}{$\begin{array}{l}\text { Simulated max. } \\
(\mathrm{ppm})\end{array}$} & \multicolumn{2}{|c|}{$\begin{array}{c}\text { Expected exceedance }(\%) \text { of } \\
9 \mathrm{ppm}\end{array}$} \\
\hline & & & Median & Range \\
\hline 1. & $\begin{array}{l}\text { Adult workers commuting by public bus } \\
\text { daily }(10: 00-18: 00) \\
\text { In office* }(5 \mathrm{~h} \text {, noon })+\ddagger+\text { on sidewalk } \\
(2 \mathrm{~h} \text {, noon })+\text { at bus stop }(20 \text { min., EP) } \\
+ \text { in bus }(40 \text { min., EP) }\end{array}$ & 30 & 4 & $3.5-5.5$ \\
\hline 2. & $\begin{array}{l}\text { Roadside business workers } \\
(7: 00-15: 00) \\
\text { At corridor }(2 \mathrm{~h}, \mathrm{MP})+ \\
\text { at corridor }(6 \mathrm{~h}, \text { noon })\end{array}$ & 80 & 31 & $29-34$ \\
\hline 3. & $\begin{array}{l}\text { Bus drivers }(7: 00-15: 00) \\
\text { In bus }(2 \mathrm{~h}, \mathrm{MP})+\text { in office } *(2 \mathrm{~h} \text {, noon })+\text { in bus } \\
(4 \mathrm{~h}, \text { noon })\end{array}$ & 23 & 65 & $58-68$ \\
\hline
\end{tabular}

* Background $\mathrm{CO}$ concentration of $2.5 \mathrm{ppm}$ were assumed, as described in text.

$+\mathrm{MP}$, morning rush hour $(7: 00-9: 00)$; noon, midday $(9: 00-17: 00)$; EP, evening rush hour $(17: 00-19: 00)$

† Location (duration, time period).

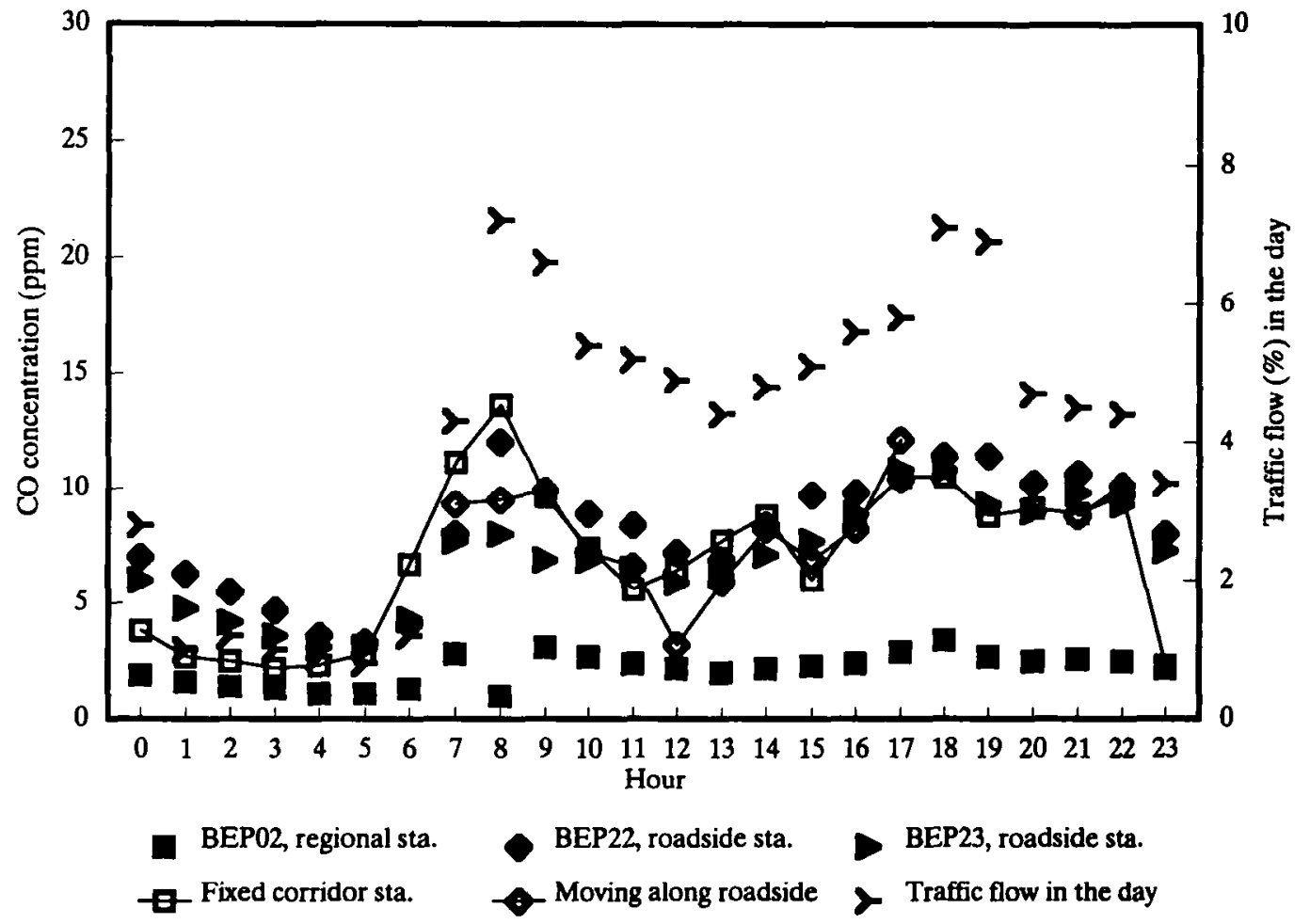

Fig. 1. Comparison of $\mathrm{CO}$ concentrations measured by fixed stations of Bureau of Environmental Protection (BEP), Taipei and by this study.

ant contributor to personal $\mathrm{CO}$ exposure levels. The $\mathrm{CO}$ concentrations (average) measured either at fixed corridors $(8.3 \mathrm{ppm})$ or by moving bag sampling along the roadsides ( $7.8 \mathrm{ppm}$ ) were very close (Table 2 ). The similarity in $\mathrm{CO}$ concentrations measured at roadside stations (BEP22, BEP23), fixed corridor stations, and movings bag samplings along the roadsides can also be observed in Fig. 1. These measurements account for the distinguishable microenvironments, such as the roadside, corridor, through which many people commute and in which many work. The discrepancy of $\mathrm{CO}$ measurements between these roadside stations and the regional stations (in residential areas) can be explained by differences in the location and height of monitoring 


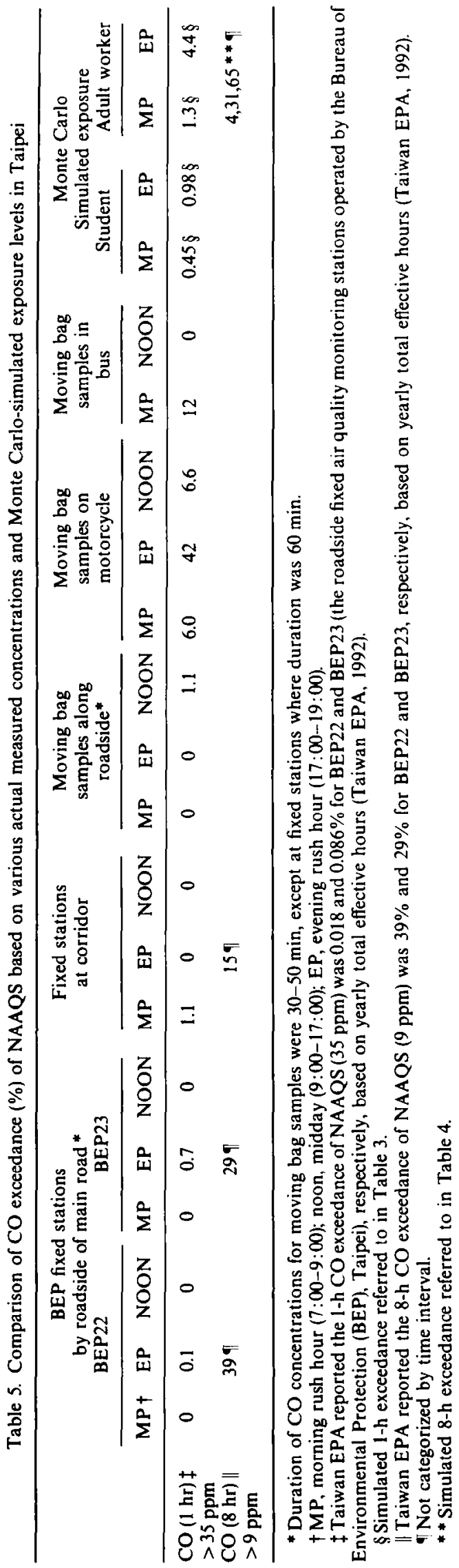

stations due to dispersion effects. CO concentrations at roadsides also showed a significant diurnal pattern (Fig. 1). This pattern corresponded to variations of traffic flow in the day in Taipei. That CO concentrations on roadsides show good correlation with urban traffic flow in the daytime suggests the direction to take in order to reduce urban air pollution. As expected, among commuters, motorcyclists suffered the highest $\mathrm{CO}$ exposure levels due to their close proximity to vehicle exhaust. Since motorcycles are a very popular mode of transportation in Taipei, special control measures must be implemented to protect motorcyclists, as well as the health of the general public. The long-term exposure levels of professional workers, such as bus drivers and roadside business workers, also need to be seriously considered.

In addition, the $\mathrm{CO}$ concentrations measured at the "regional station" (BEP02) and at the "roadside station" (BEP22, BEP23) differed greatly even though both types of stations are classified as outdoor fixed stations. These large differences demonstrated how important it is to carefully report the type of outdoor fixed stations in studies on indoor/outdoor pollutant concentration ratios and in those that assume outdoor background concentration in total exposure modeling (Fig. 1). Because the difference between $\mathrm{CO}$ measurements from regional stations and roadside stations is greatest during the rush hour, a large deviation (or error) in the upper extreme tail will occur if the two types of outdoor fixed site stations are not well distinguished.

Using the Monte Carlo method, based on actual $\mathrm{CO}$ measurements and commuting pattern data, this study simulated 1- and 8-h $\mathrm{CO}$ exposure distributions and compared them with NAAQS ( 35 or $9 \mathrm{ppm}$ ). It is demonstrated that the population-fraction term is meaningful and essential when investigating urban air pollutant exposure issues. This study predicts that a relatively high percentage of the population is exposed to CO levels greater than $35 \mathrm{ppm}$ in $1 \mathrm{~h}$ (NAAQS) in Taipei (Table 3). Moreover, an adult worker's expected $\mathrm{CO}$ exposure exceedance $(5.69 \%)$ is about 4 times higher than a student's $(1.44 \%)$. For students, there is expected (population-weighted) exceedance of $1.19 \%$ when commuting by public buses. For adult workers, a higher expected (population-weighted) exceedance occurred when commuting by motorcycle $(3.25 \%)$ or by bus $(2.44 \%)$. Adult workers have higher $\mathrm{CO}$ exposure levels than students because they commute for longer duration, encounter more traffic jams, and are exposed to higher $\mathrm{CO}$ concentrations on motorcycles. The adult workers' expected $\mathrm{CO}$ exposure exceedance during the evening rush hour is about 3-4 times that of the morning rush hour, probably because of the longer commuting duration (Table 1) and more extreme $\mathrm{CO}$ concentrations for motorcyclists during the evening rush hour. The simulated 8$\mathrm{h} \mathrm{CO}$ exposure for the three assumed common scenarios were compared to NAAQS. This study found that 
the 8-h CO exposure levels for adult workers were high, and were even higher for adults working along and on the roads. The expected $\mathrm{CO}$ exposure exceedances for an 8 -h period were 4,31 , and $65 \%$ for adult workers commuting by public buses, roadside business workers and bus drivers, respectively. In extreme cases, the 8-h $\mathrm{CO}$ exposure levels can be 3-8 times higher than the NAAQS. Since there are many small shops on both sides of main traffic roads in Taipei, the problems of $\mathrm{CO}$ exposure among roadside workers and businessmen should not be overlooked. An even more important implication of the simulated findings is that there is a need to reduce the $\mathrm{CO}$ exposure levels for bus drivers, taxi drivers, traffic controllers, and other people with these occupational risk in Taipei. If it is warranted, more scenarios and simulations can be undertaken and more about the simulated exposure distributions can be obtained and be assessed.

In order to test the representativeness of BEP fixed stations, this study compared the expected $\mathrm{CO}$ exposure levels determined by the Monte Carlo simulation with that of two BEP roadside monitoring stations (BEP22, BEP23) in Taipei (Table 5). It was found that the measurements by $B E P$ fixed roadside stations underestimated the short-term $\mathrm{CO}$ exposure levels (1h) as simulated by the Monte Carlo simulation. On the other hand, the measurements of BEP fixed roadside stations reasonably estimated the roadside business worker's 8-h $\mathrm{CO}$ exposure levels, as compared with the simulation results. However, the measurements of roadside stations overestimated 8 -h exposure levels for adult workers commuting by bus, but underestimated 8 -h exposure levels of bus drivers. The unrepresentativeness of roadside stations in estimating 1-h exposures can be explained by the dispersion effect in which $\mathrm{CO}$ concentrations are lower at roadside stations, which are several meters away from the side lanes of traffic roads and above the commuter's breathing zones (1-1.5 $\mathrm{m}$ ) than in the real exposure zones. The problem of unrepresentativeness was less serious in estimating 8-h exposure levels because there is an averaging effect which evens out peak exposure events over the exposure period. The upper end of the CO concentration distribution at the exact detection point away from sources was determined through dispersion effect. It was expected that with nearer distances or shorter averaging times, greater upper extremes, higher exceedances and higher risks would be calculated. If the NAAQS level was shifted, the exceedance values would change to an extent depending on the upper tail shape. More works can be conducted to determine the severity of air pollutant exposure and the representativeness of measurements in different contexts. Although the findings in this study on representativeness of fixed site monitoring are based on Taipei's actual $\mathrm{CO}$ measurements only, this study emphasizes the importance and the effect that local physical settings and population lifestyle can have on personal pollution exposure levels assessment significantly in an urban area setting.

Acknowledgements-This study was financially supported by the Bureau of Environmental Protection in Taipei City, and the Taiwan Environmental Protection Agency. The data analysis was largely helped by the coworkers of one researcher (Mr Jyh-Jian Liu) at CTCI Co. We all feel greatly indebted to the above individuals and institution.

\section{REFERENCES}

Billick H. I., Özkaynak H., Butler D. A. and Spengler J. D. (1991) Predicting personal exposures to $\mathrm{NO}_{2}$ for population-based exposure and risk evaluations. In 84th Annual Meeting of $A W M A$, Vancouver, British Columbia, 16-21 June. AWMA, Pittsburgh, PA.

Chan C. C., Özkaynak H., Spengler J. D. and Sheldon L. (1991) Driver exposure to volatile organic compounds, $\mathrm{CO}$, ozone, and $\mathrm{NO}_{2}$ under different driving conditions. Envir. Sci. Technol. 25, 964-972.

Cortese A. D. and Spengler J. D. (1976) Ability of fixed monitoring stations to representative personal carbon monoxide exposure. JAPCA 26, 1144-1150.

Eskridge R. E. (1987) ROADWAY -A numerical model for predicting air pollutants near highways. NTIS PB87-171906, U.S. EPA.

Fingleton D. A., McDonnell M. M., Özkaynak H., Xue J. and Butler D. A. (1991) Stochastic model for estimation personal exposures in contaminated buildings at Superfund sites. In 84th Annual Meeting of $A W M A$, Vancouver, British Columbia, 16-21 Junc. AWMA, Pittsburgh, PA.

Hewitt C. N. (1992) Spatial variations in nitrogen dioxide concentrations in an urban area. Atmospheric Environment 25B, 429-434.

Hoydysh W. G. (1988) Kinematics and dispersion characteristics of flow in asymmetric street canyons. Atmospheric Environment 22, 2677-2689.

ICF Kaiser Engineers, Inc. (U.S.) and CTCI Corp. (Taiwan) (1991) Total Air Pollutants Emission Quantity Investigation and Reduction Planning for the Northern, Central, and Southern Parts of Taiwan. Contracted by Taiwan EPA, Taipei, Taiwan.

Johnson T. R., Paul R. A., Capel J. E. and McCurdy T. (1990) Estimation of ozone exposure in Houston using a probablic version of NEM. In 83rd Annual Meeting of $A W M A$, Pittsburgh, Pennsylvania, 24-29 June. AWMA, Pittsburgh, PA.

Ott W. R. (1983-84) Exposure estimates based on computer generated activity patterns. J. Toxicol-Clin. Toxicol. 21 (1 and 2), 97-128.

Ott W. R., Thomas J., Mage B. and Wallace L. (1988) Validation of simulation of human acitivity and pollutant exposure (SHAPE) model using paired day data from the Denver Co., carbon monoxide field study. Atmospheric Environment 22, 2101-2113.

Ryan P. B., Soczek M. L., Treitman R. D., Spengler J. D. and Billick H. I. (1988) The Boston residential $\mathrm{NO}_{2}$ characterization study-II. Survey methodology and population concentration estimates. Atmospheric Environment 22, $2115-2125$.

Sexton K. and Ryan P. B. (1988) Assessment of human exposure to air pollution: method, measurements, and models. In Air Pollution, the Automobile, and Public Health (edited by Watson A. Y., Bates R. R. and Kennedy D.). National Academy Press, Washington, D.C. 
Taiwan EPA (1991) The 1990 Yearbook of Local Environmental Information in Taiwan. Taipei, Taiwan (in Chinese).

Taiwan EPA (1992) The Annual Assessment Report of the Air Pollution Control in Taiwan Area for 1990. Taipei, Taiwan (in Chinese).
U.S. EPA (1990) Guideline on Air Quality Models (Revised). EPA-450/2-78-027R, Office of Air and Radiation, Office of Air Quality Planning and Standards, Research Triangle Park, NC. 